\title{
BMJ Open Blood donation from 2006 to 2015 in Zhejiang Province, China: annual consecutive cross-sectional studies
}

\author{
Wei Hu, ${ }^{1,2}$ Hongdao Meng, ${ }^{3}$ Qiuyue Hu, ${ }^{1}$ Lijuan Feng, ${ }^{3}$ Xianguo $\mathrm{Qu}^{4}$
}

To cite: Hu W, Meng $\mathrm{H}$, Hu $Q$, et al. Blood donation from 2006 to 2015 in Zhejiang Province, China: annual consecutive crosssectional studies. BMJ Open 2019;9:e023514. doi:10.1136/ bmjopen-2018-023514

- Prepublication history for this paper is available online. To view these files please visit the journal online (http://dx.doi org/10.1136/bmjopen-2018023514).

Received 17 April 2018 Revised 15 April 2019 Accepted 17 April 2019
Check for updates

(C) Author(s) (or their employer(s)) 2019. Re-use permitted under CC BY-NC. No commercial re-use. See rights and permissions. Published by BMJ.

${ }^{1}$ Blood Center of Zhejiang Province, Hangzhou, China

${ }^{2}$ Key Laboratory of Blood Safety Research of Zhejiang Province, Hangzhou, Zhejiang, China ${ }^{3}$ School of Ageing Studies, University of South Florida Tampa, Florida, USA

${ }^{4}$ The First Affiliated Hospital of Zhejiang Chinese Medicine University, Hangzhou, China

Correspondence to Wei Hu; hw@zjb.org.cn

\section{ABSTRACT}

Objectives To describe the basic demographical characteristics of whole blood donors in Zhejiang Province, China, from 2006 to 2015 and to examine the trends in individual characteristics associated with blood donation and the relationship between weight and donation.

Design Cross-sectional study comparing characteristics of blood donors and annual donations for the period 2006 to 2015.

Setting Urban and rural communities in Zhejiang, China (11 cities, 89 districts or counties and 1379 townships).

Participants 3226571 volunteer blood donors. Outcome measures Volume of each whole blood donation and donation frequency. All data were collected by trained staff and entered into a standardised electronic information system.

Results The number of blood donations generally trended up in Zhejiang Province from 2006 to 2015. Donors were predominately males aged 18 to 25 years, but this major donor age group shifted to the 26 to 45 year range by 2015. The rate of repeated blood donation was 30.8 per cent. The blood volume per donation concentrated in $200 \mathrm{~mL}$ and $400 \mathrm{~mL}$ categories has been gradually shifted to $300 \mathrm{~mL}$ and $400 \mathrm{~mL}$. Approximately one-third of donors had a college education. The average weight of donors increased over time for both men and women. Both the blood volume of each donation and donation frequency were proportional to weight.

Conclusions The trend of voluntary non-remunerated blood donation in Zhejiang province is positive. However, given the expected growth in demand for whole blood, more research is needed to increase both the donor pool and the rate of repeated donation. The relationship between body weight and blood donation warrants further study because while improving nutritional status is associated with higher average donation volume and more frequent donations, overnutrition may lead to poorer quality of donated blood. Blood donation may present a unique opportunity for health education and body weight management to monitor and improve population health.

Sufficient and safe blood supply has always been a vital part of any healthcare system. A recent WHO report indicated that every year the median whole blood donation per 1000 population differs with different income levels, which was 32.1 in high-income countries, 14.9 in upper-middle-income countries,

\section{Strengths and limitations of this study}

This study is the largest scale study in blood donation of any province in China in terms of sample size and time span.

- The provincial-wide blood donation information system provides consistent data in a large and well-defined geographical area.

- All donors with repeated donations were identified by the unique national identification number thus ensuring accurate information on repeated donations.

- To encourage blood donation and minimise respondent burden, the scope of data collection was limited.

- The study was conducted in Zhejiang province in China thus the results may not be generalisable to other parts of China.

7.8 in lower-middle-income countries and 4.6 in low-income countries. ${ }^{1}$ South-East Asia had the highest percentage increase $(75 \%)$ in voluntary non-remunerated blood donation (VNRBD) among 159 countries from 2008 to $2013,{ }^{1}$ whereas a downward trend was evident in some European countries. ${ }^{2}$ As the world's most populous and the largest developing country, China has made great progress in blood donation. From 1998 to 2016, China's annual blood collection increased by $377 \%$ from 4950000 units to 23600000 units. ${ }^{34}$ The blood donation rate (median) per $1000 \mathrm{popu}-$ lation in China has increased from 0.04 in 1998 to 10.5 in $2016,{ }^{45}$ and blood component transfusion rate (proportion of blood component products transfused as the percentage of all blood transfusion) has reached $99.6 \% .{ }^{4}$ In 2016 , the blood donation rate (median) in Zhejiang province was 11.8 donations per 1000 population, higher than the national average of 10.5, but still falls short of meeting the need for clinical transfusion. In 2005, the proportion of blood donations from VNRBD reached $100 \%$ in Zhejiang province, earlier than the nation. ${ }^{6}$ 
To better understand donors, knowledge about donor characteristics, such as demographical profiles, is required to describe the composition of the donor population. Insight into donor characteristics is essential for targeted donor recruitment and donor retention. ${ }^{7-10}$ Demographical characteristics varied among countries or region. Data from 118 countries on the profile of blood donors show that, overall, $70 \%$ of blood donations were given by male donors, and $40 \%$ of donations were given by donors aged 25 to 44 years. ${ }^{1}$ Among the 1.39 billion people in China in 2017, the number of seniors, aged 60 and above, reached 240.9 million, which accounted for $17.3 \%$ of the total population; aged 65 and above reached 158.31 million and accounted for $11.4 \% .{ }^{11}$ Due to the rapid economical development in China and the notable improvement in the quality of meals, people of all age groups in China have gained more body weight. The growth rate of body weight tends to increase with age. ${ }^{12}$ Based on the assumption that blood volume can be estimated as $70 \mathrm{~mL} / \mathrm{kg}$, body weight was one of the key selection criterions. The American Association of Blood Banks (AABB) standard for minimum donor weight of $110 \mathrm{lb}(50 \mathrm{~kg})$ and to limit collection to $10.5 \mathrm{~mL} / \mathrm{kg}$ is sufficient to protect most people, and to limit blood loss to no more than $15 \%$ of a person's total blood volume. ${ }^{1314}$ Furthermore, body weight is a very important determinant of vasovagal reaction rates in first-time donors. ${ }^{15-17}$ However it does not mean that higher body weight is always beneficial to blood donation. Overnutrition and overweight also represent a negative impact on blood donation, since obesity causes or exacerbates a large number of health problems and is among the most significant contributors to poor health. ${ }^{18}$ As the rate of obesity in youth and young adults has approximately tripled in China, how to reverse the trend of increasing prevalence of obesity remains one of the biggest public health challenges among developing and middle-income countries. ${ }^{19}$ Despite the importance of body weight for individual and population health, research on the body weight has largely been focused on the adverse events of blood donation. ${ }^{15-17}$ Currently, few studies have examined the relationship between body weight and the frequency of blood donation. This paper describes demographical and anthropometrical factors associated with blood donation behaviour of VNRBD in Zhejiang province. It provides a specific analysis of blood donor demographical characteristics to increase repeated blood donations and ultimately to ensure adequate safe blood sources. This study is unique in several aspects. Zhejiang province is the only province in China with an integrated electronic donation information system since 2001. This system collects data covering the entire blood collecting, testing and distributing process. As a result, Zhejiang province has a unique advantage in blood donation data collection and statistical analysis. Also, the gender-specific body weight analysis offers insight into the future development of gender-specific donor recruitment and retention strategies as healthy lifestyles help maintain healthy body weight, which in turn increases the base of healthy recruitable donors.

\section{METHODS}

\section{Study setting and design}

According to China's National Regulation of Blood Banks (2005), ${ }^{20}$ blood banks are established by the local government health authorities based on the regional population, medical resources, clinical demand for blood and the development of local health planning. Blood banks are non-profit public health agencies responsible for the collection, preparation, storage of blood and supply blood to healthcare facilities. The government's Bureaus of Healthcare Administration are responsible for the planning, supervision and management of blood banks. There are a total of 38 blood banks in Zhejiang province, including one provincial blood centre, 11 municipal blood stations and 26 district blood banks or central blood banks or blood collection sites. Collections are conducted in fixed blood donation stations in urban areas and mobile collection vehicles (for collections at the worksite or temporary locations in rural areas).

According to China's national regulations on blood donation, after registration and physical examination on the donation site, professional staff will offer advice, and the donors can ultimately decide to donate $200 \mathrm{~mL}$, $300 \mathrm{~mL}$ or $400 \mathrm{~mL}$. The amount of blood donated is determined voluntarily. Blood donors must be between 18 and 55 years old (expanded to 60 in 2012). In 2012, 'blood donor health examination requirements' (GB184672011) was issued. Repeated blood donors who met the health check-up requirements and no previous adverse reaction, the age limit can be extended to 60 years old. Consistent with international practice, $200 \mathrm{~mL}$ plus or minus 10 per cent ( 180 to $220 \mathrm{~mL}$ ) is classified as $200 \mathrm{~mL}$, $300 \mathrm{~mL}$ plus or minus 10 per cent ( 270 to $330 \mathrm{~mL}$ ) is classified as $300 \mathrm{~mL}, 400 \mathrm{~mL}$ plus or minus 10 per cent (360 to $440 \mathrm{~mL}$ ) is classified as $400 \mathrm{~mL}$ and the rests are classified as non-standard amount. The minimum interval between the two whole blood donations is 6 months. The minimal body weight requirement is $50 \mathrm{~kg}$ for men and $45 \mathrm{~kg}$ for women.

The present study used a cross-sectional study design by comparing the characteristics of blood donors and annual donations for the period 2006 to 2015.

\section{Patient and public involvement}

There is no direct patient and public involvement in this study. This study utilised a retrospective analysis of an existing blood donation database to analyse the data of blood donors that have already been collected in the database. For this study, all whole blood donations ( $\mathrm{n}=5299$ 729) of 3226571 VNRBDs between 2006 and 2015 were extracted from the Zhejiang provincial blood management information system. This study period was chosen because no major system modification happened during this period, thus ensuring consistent information 
collection and processing. Because of the different ways to donate and different donation interval requirements, all apheresis donations were excluded to eliminate interference.

\section{Measures}

The database includes donors' basic demographical characteristics such as age (in years), gender (male, female), education level (classification according to GB184672011), occupation (classification according to GB184672011), body weight (used for eligibility assessment, $\mathrm{kg}$ ) and blood collection information, such as date (month/ date/year), time (24hours), volume $(\mathrm{mL})$ and frequency of blood donations (one time, two times, etc).

Single-time blood donors are those who have donated blood only one time in their whole blood donation career. First-time blood donors are donors who donate blood for the first time regardless of whether the donor was a single-time donor or multiple-time donor.

Due to the complexity and privacy of occupations, 105 blood donors chose not to fill in the column of occupation. Because of this, their employment status information was missing. The occupation of these donors was included in the category 'other'.

\section{Statistics analysis}

Data extraction was performed by using structured query language. After data extraction, a retrospective analysis of the data, including descriptive statistics and logistical regression analysis, were performed by using IBM SPSS V.21. We used the Strengthening the Reporting of Observational Studies in Epidemiology checklist for cross-sectional studies to guide the structure of the written report. ${ }^{21}$

We performed a descriptive analysis of basic individual characteristics of blood donors using the 2006 to 2015 dataset and then examined the trend in donor characteristics and blood donated volume over time. To accurately reflect the proportion of people who donated blood in the trend analysis, only the second donation record was included for individuals who donated twice in a calendar year. We also use descriptive statistical methods to examine the characteristics of blood donors by body weight categories for men and women. Finally, we use logistical regression to examine the relationship between donor demographical characteristics and the volume and likelihood of repeated donation. Because the body weight eligibility criteria for blood donation differs by gender, we performed the regression analyses separately for men and women.

\section{RESULTS}

From 2006 to 2015, a total of 3226571 individuals donated 5299729 times of whole blood in Zhejiang province (table 1). Overall, the 18- to 25-year-old donor group accounted for $45 \%$ of the total blood donors, the 26- to 35 -year-old group and 36- to 45-year-old group accounted for $28.4 \%$ and $19.1 \%$, respectively. The proportion of
Table 1 Characteristics of whole blood donors in Zhejiang Province, China, 2006 to 2015 ( $n=3226571$ )

\begin{tabular}{|c|c|c|}
\hline Variable & $\begin{array}{l}\text { Number of blood } \\
\text { donors }\end{array}$ & $\%$ \\
\hline \multicolumn{3}{|c|}{ Age category, years } \\
\hline $18-25$ & 1451025 & 45.0 \\
\hline $26-35$ & 914745 & 28.4 \\
\hline $36-45$ & 617108 & 19.1 \\
\hline $46-55$ & 236807 & 7.3 \\
\hline 56 & 6886 & 0.2 \\
\hline \multicolumn{3}{|l|}{ Gender } \\
\hline Male & 1859599 & 57.6 \\
\hline Female & 1366972 & 42.4 \\
\hline
\end{tabular}

\section{Education}

\begin{tabular}{lrr} 
Elementary school & 71755 & 2.2 \\
Middle school & 805520 & 25.0 \\
\hline High school & 829755 & 25.7 \\
University* & 1173456 & 36.4 \\
Postgraduate & 26228 & 0.8 \\
\hline Other† & 254799 & 7.9 \\
Missing & 65058 & 2.0 \\
Occupation & & \\
Students & 495258 & 15.3 \\
Clerk & 450757 & 14.0 \\
Workers & 330120 & 10.2 \\
Farmers & 213674 & 6.6 \\
Medical worker & 121665 & 3.8 \\
Public service & 109410 & 3.4 \\
\hline Other†+ & 1505687 & 46.6
\end{tabular}

Male weight, $\mathbf{k g}$

$\begin{array}{lrr}50-59 & 309616 & 16.6 \\ 60-69 & 741369 & 39.9 \\ 70-79 & 548789 & 29.5 \\ 80-89 & 204912 & 11.0 \\ \geq 90 & 54913 & 3.0\end{array}$

\section{Female weight, kg}

$\begin{array}{lrr}45-49 & 249689 & 18.3 \\ 50-54 & 420068 & 30.7 \\ 55-59 & 316089 & 23.1 \\ 60-64 & 213947 & 15.7 \\ 65-69 & 95368 & 7.0 \\ \geq 70 & 71811 & 5.3 \\ \text { Donation frequency } & & \\ \text { One } & 233693 & 69.2 \\ \text { Two } & 525215 & 16.3 \\ \text { Three or more } & 467663 & 14.5\end{array}$

Donation volume per time, $\mathrm{mL}$ 


\begin{tabular}{|c|c|c|}
\hline Variable & $\begin{array}{l}\text { Number of blood } \\
\text { donors }\end{array}$ & $\%$ \\
\hline $200 \pm 200 \times 10 \%$ & 918678 & 28.5 \\
\hline $300 \pm 300 \times 10 \%$ & 1144307 & 35.5 \\
\hline $400 \pm 400 \times 10 \%$ & 1138942 & 35.3 \\
\hline Non-standard amount & 24644 & 0.8 \\
\hline
\end{tabular}

*'University’ including junior college degree and bachelor degree. †Other' including lower than elementary school or higher than postgraduate.

¥'Other' including missing and other types of occupations. $\mathrm{kg}$, kilogram; $\mathrm{mL}$, millilitre.

male donors remained stable $(57.6 \%)$. College educated donors are the largest group of blood donors (36.4\%), followed by those with high school $(25.7 \%)$ and middle school (25\%) education. The body weight of blood donors was concentrated in the 60 to $79 \mathrm{~kg}$ group (69.4\%) for men and the 50 to $59 \mathrm{~kg}$ group $(53.8 \%)$ for women.

Regarding repeated donation, the great majority $(69.2 \%)$ of donors only donated once, $16.3 \%$ donated twice and $14.5 \%$ donated three or more times. Thus, the repeated donation rate of $30.8 \%$ is much lower than the world average of $50 \% .^{1}$ Donors mainly donated blood volume of either $300 \mathrm{~mL}(35.5 \%)$ or $400 \mathrm{~mL}(35.3 \%)$ each time.

\section{Trend}

As shown in figure $1-8$, the number of blood donors generally increased over the 10 year period reaching a maximum of 540284 in 2015. The age structure of blood donors changed substantially from 2006 to 2015, with the average age rising from 28.6years old to 32.8 years old over the study period, an increase of 4.2 years. As a result, the proportion of younger donors (18 to 25 years) decreased from $48.2 \%$ in 2006 to $30.7 \%$ in 2015 . The $26-$ to 35-year-old group is the more stable donor group, with an average of about $30 \%$. Interestingly, the proportion of people aged 36 to 45 and 46 to 55 increased significantly; the former increased 8.2 percentage points (from $17.7 \%$ in 2006 to $25.9 \%$ in 2015 ), while the latter increased 7.9 percentage points (from $4.9 \%$ to $12.8 \%$ ). The results

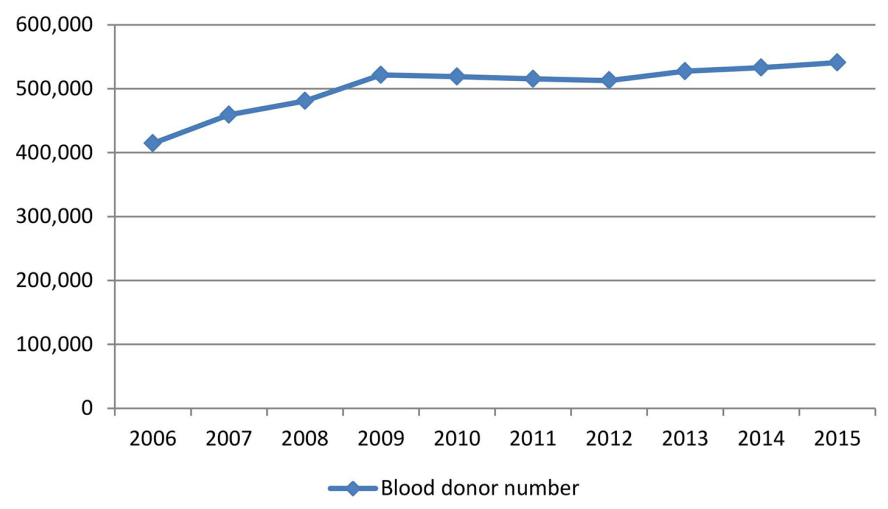

Figure 1 Blood donor numbers.

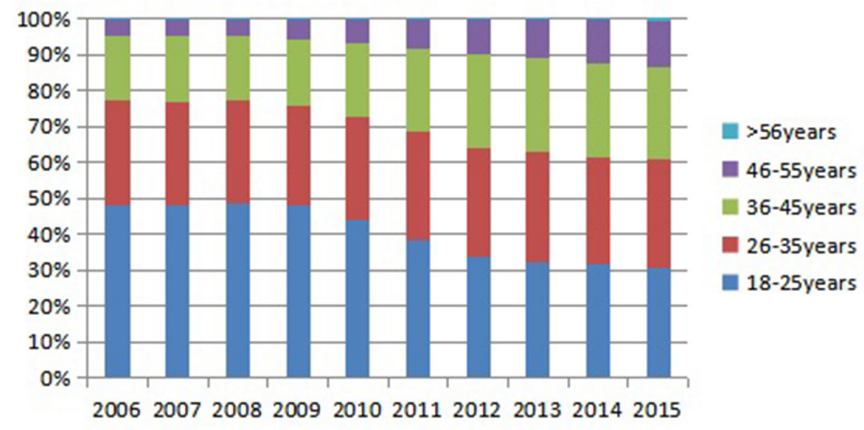

Figure 2 Age category (years).

show that the changing trend of the age structure of blood donors is the same as the direction of population ageing, with the focus shifted from the lower age group to the middle age group. Since 1 July, 2012, the proportion of people over the age of 56 increased slowly.

Regarding the trend of whole blood donation, men were consistently more likely to be donors as compared with women. For the female donor number, the year of 2009 seems to be a turning point, with upward trending until 2009 and downward trending after 2009. In the entire population, $1.02 \%$ of men in Zhejiang donated blood in 2006; the proportion rose to $1.34 \%$ in 2015 . The corresponding rates were $0.76 \%$ and $0.88 \%$, respectively, for women. Compared with men, this may relate to the fact that women are at risk for iron depletion because of menstruation ongoing blood loss, recent pregnancies and inadequate dietary iron. ${ }^{22}$ Female metabolic syndrome prevalence was 2.14 times higher in donors with high donation intensity compared with those with low donation intensity. ${ }^{23}$

Regarding blood volume of each donation, the proportion of $200 \mathrm{~mL}$ showed a declining trend, $300 \mathrm{~mL}$ with an overall upward trend. The proportion of $400 \mathrm{~mL}$ dropped first and then increased, similar to Shenzhen. ${ }^{24}$ This is related to the gradual promotion of $300 \mathrm{~mL}$ size of blood donation began in Zhejiang province in 2007. Regarding the trend of educational level, the proportion of universities increased with small fluctuations, accounted for nearly $40 \%$ by 2015 , while the proportion of high schools dropped year by year, from $28.6 \%$ in 2006 to $22.5 \%$ in 2015 , and others are relatively stable.

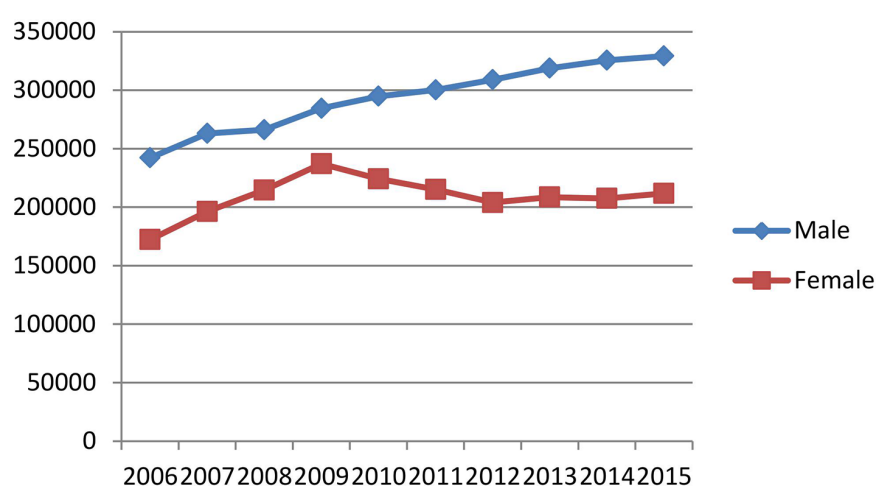

Figure 3 Gender. 


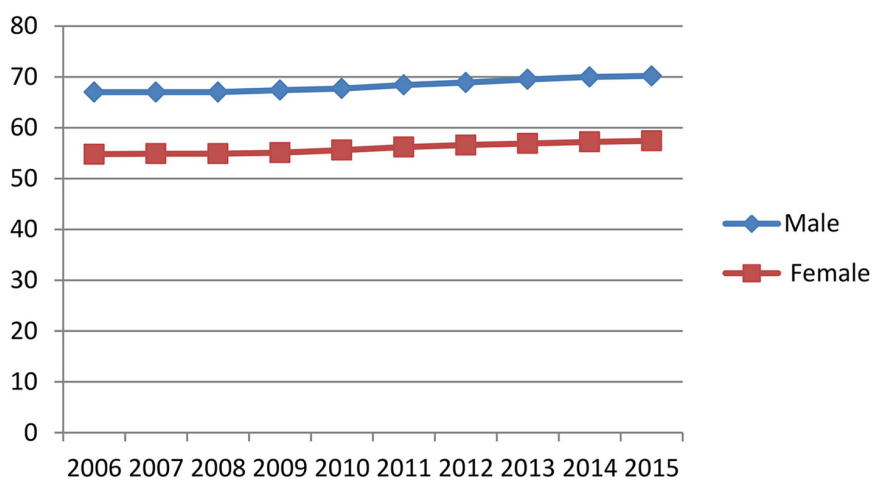

Figure 4 Average body weight (kg). kg, kilogram.

The trend in body weight is generally upward for both men and women between 2006 and 2015 (figure 4). The average body weight of male blood donors increased from $67.0 \mathrm{~kg}$ to $70.2 \mathrm{~kg}$, an increase of $3.2 \mathrm{~kg}(4.8 \%)$ while that of women increased from $54.8 \mathrm{~kg}$ to $57.4 \mathrm{~kg}$, an increase of $2.6 \mathrm{~kg}(4.7 \%)$. The major body weight among male donors gradually shifted from 60 to $69 \mathrm{~kg}$ to 70 to $79 \mathrm{~kg}$, whereas female donors were still 50 to $59 \mathrm{~kg}$, but body weight of female donors over $60 \mathrm{~kg}$ is gradually increasing. Among men, the proportion of lower-weight group decreased significantly (8.1 per cent in the 50 to 59 $\mathrm{kg}$ group and 6.1 per cent in the 60 to $69 \mathrm{~kg}$ group). In contrast, the proportion weighed between 70 and $79 \mathrm{~kg}$ had a $6.8 \%$ increase; the same increase proportion was 5.4 and 2.1 per cent for those weighed 80 to $89 \mathrm{~kg}$ and $90+\mathrm{kg}$, respectively. Similar patterns of a decreasing proportion of lower-weight group and an increasing proportion of higher-weight group were observed among women.

\section{Demographical factors and blood donation behaviour by gender}

Table 2 shows that low body weight donors were younger and with low donation volume for both men and women. The rate of repeated donation gradually increased with body weight for both men and women. For men, the rate of repeated donation increased 19 per cent in the subgroups ranging from 50 to $59 \mathrm{~kg}$ to 80 to $89 \mathrm{~kg}$, and that of women also increased 19 per cent in the subgroups ranging from 45 to $49 \mathrm{~kg}$ to over $70 \mathrm{~kg}$. The rate of donating $400 \mathrm{~mL}$ per time was associated with increasing

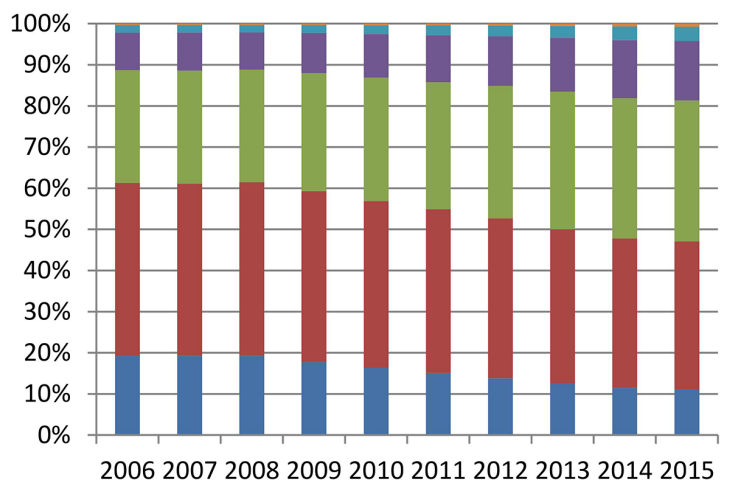

$>99 \mathrm{~kg}$

च $90-99 \mathrm{~kg}$

- $80-89 \mathrm{~kg}$

- $70-79 \mathrm{~kg}$

- $60-69 \mathrm{~kg}$

- $50-59 \mathrm{~kg}$

2006200720082009201020112012201320142015

Figure 5 Male donor body weight category. kg, kilogram.

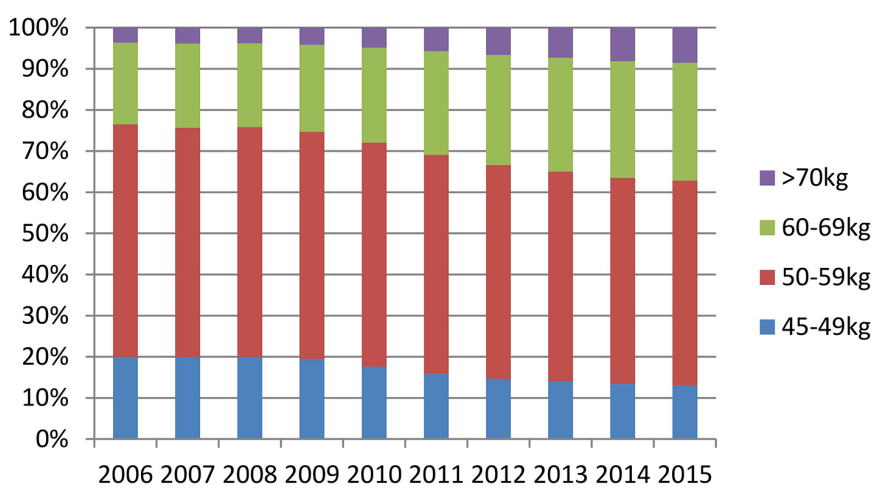

Figure 6 Female donor body weight category. kg, kilogram.

body weight too. For men, the rate of $400 \mathrm{~mL}$ donations increased 49.7 per cent from 50 to $59 \mathrm{~kg}$ to over $90 \mathrm{~kg}$, and that of women also increased 47.9 per cent from 45 to $49 \mathrm{~kg}$ to more than $70 \mathrm{~kg}$.

Table 3 and table 4 showed that all individual characteristics (age, body weight, education level and occupation) were independently associated with the volume of each donation and donation frequency for both men and women. The likelihood of repeated donation increased with age. For donors with high school or higher education, the likelihood of donating $300 \mathrm{~mL}$ or more decreased, but repeated donations increased. We also found that repeated donation and blood volume each donation for both male and female blood donors in Zhejiang were directly proportional to body weight, the heavier the blood donor is, the larger the likelihood of more volume of blood each donation is and more frequent the blood donation is. Among different occupations, medical workers showed a high likelihood of repeated donations.

\section{DISCUSSION}

Our study aimed to identify the trends in whole blood donation and examine the demographical characteristics associated with the volume and frequency of donations in Zhejiang from 2006 to 2015. The results revealed that the average age of blood donors increased, and the proportion of donors aged 18 to 25 declined over time. Body weight is generally proportional to donation volume and donation frequency.

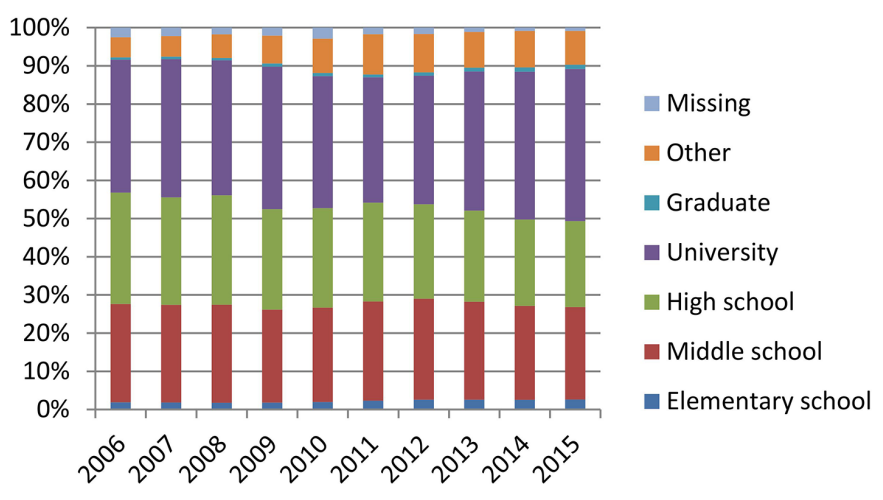

Figure 7 Education. 


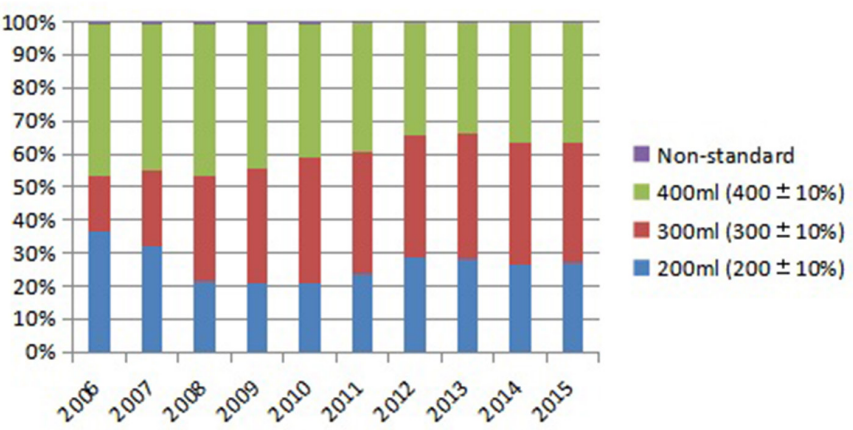

Figure 8 Donation volume per time $(\mathrm{mL}) . \mathrm{mL}$, millilitre.

The proportion of male donors is similar to findings from Shenzhen and Hong Kong. ${ }^{24-27}$ Compared with data reported from a total of 80 countries (23 high-income, 18 upper-middle-income, 22 lower-middle-income and 17 low-income), ${ }^{1}$ the overall age structure of Zhejiang blood donors was younger than the global average. This maybe mainly related to the relatively younger age structure of the populations in developing countries.

The trend of blood donor number is a little different from the European Union (EU). The donor population of the EU rose significantly from 1994 to 2009, then stabilised thereafter, with a small decrease later in 2014. ${ }^{28}$ This may partly be due to the widely used patient blood management in the EU, which emphasises on minimising the need for transfusion, thus reducing the potential risks and costs, and sparing limited resource. ${ }^{29}{ }^{30}$ As we mentioned in the introduction, Zhejiang province was still far behind developed countries in terms of the number of donations per 1000 population, so it still belongs to the demand market. The measures to optimise recruitment, retention and transfusion in Zhejiang work, but not significantly.

The low repeated blood donation rate after the first donation appears to be a global phenomenon, ${ }^{31-35}$ with nearly half of first-time donors remaining single-time donors. ${ }^{36}$ The loss of first-time blood donors in Zhejiang is serious. Donors' retention plays a very important role in increasing stable blood sources, reducing blood shortage and improving blood safety. ${ }^{37-40}$ Considering the loss of blood donors who only donate once, it is crucial to carry out recruitment measures to promote repeated blood donation. The finding that medical worker has a high likelihood of repeated donation may be attributable to better altruism and professional awareness, as well as province-wide campaigns such as the 'Angel guarding life'. Perhaps similar campaigns can be developed for other service occupations such as clerks and public service workers in the future.

Changes in the number of blood donations may be related to the overall changes in social environment, policy, major events (disasters, etc) and public sentiment. In 2009, The National Ministry of Health Department and the Red Cross Society of China published 'Revised National Guidelines for Non-monetary Rewards for Blood Donation'. The social atmosphere of blood donation was good in 2008 and 2009, so the number of blood donors reached high in 2009. GB18467-2011 further expanded the age to 60 years old and raised the requirement of female haemoglobin from $\geq 110 \mathrm{~g} / \mathrm{L}$ to $115 \mathrm{~g} / \mathrm{L}$. However, negative reports about the Red Cross in 2010 and 2011 led to a loss of confidence in blood donations, which resulted in a decrease in blood donor number. Female blood donors were reduced to the nadir in 2012. In response, blood banks have promoted transparency in blood management to the general public with regular updates and reports published. The number of blood donors has slowly risen year by year. Among them, there are three groups, donors aged 18 to 25 years, students and females, which have the same changing shape of the trend as the above overall blood donation. It showed that these three groups are greatly influenced by the public opinion. Social marketing strategies may be developed to strengthen positive public opinion and offer guidance and emotional support for blood donation. This is especially relevant in light of the finding that the proportion of female blood donation has been in a downward trend since 2009.

While provincial population data were not available for the entire study period, data from 2013 to 2015 show that the population base of 18 to 35 and 36 to 60 years old in Zhejiang province decreased, ${ }^{41}$ which may have accounted for the observed changes in the age structure of blood donors. Although the age group of 18 to 25 always dominated, the proportion of donors aged 18 to 25 declined obviously. Correspondingly, the proportion of people aged 36 and above continues to increase. The rate of blood donation among 18- to 35-year-old in Zhejiang province decreased first and then increased from 2013 to 2015, while that of 36- to 60-year-old increased slowly. This data suggests that the 18- to 25 -year-old population participation rate show fluctuations. Although many people meet the conditions of blood donation, only a very small minority of people are donating blood. ${ }^{42}$ We also showed that population ageing is likely to reduce the number of prospective eligible donors in the legal age range. ${ }^{25}$ The increase in average age of blood donor suggested that research is needed for maintaining the donor pool among young adults. While young adults remain the predominant basis for the present and future blood donation recruitment, education and research should examine how to promote voluntary blood donation for all age groups of the eligible population. Recruitment messages may need to be tailored to individuals from different age groups. Considering that the 18 to 25 years old are mainly college students who are likely to have different channels for media consumption and considering that the new generation has very different value systems and strong personalities, blood establishments should adapt their education tools and methods to accommodate this condition to increase their interests in blood donation.

Body weight has a major impact on a person's blood donation volume per time and blood donation frequency. This finding has mixed public health implications in that 


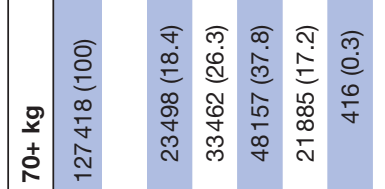

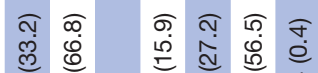

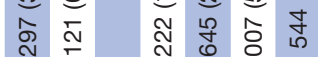

当

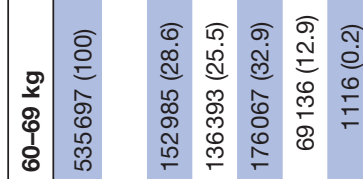

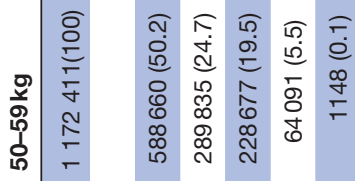

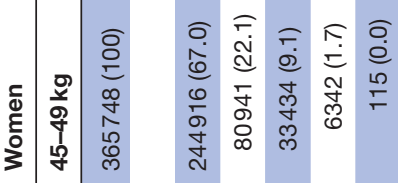

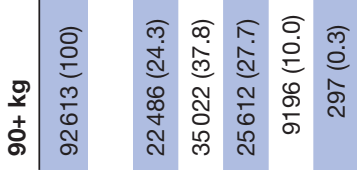

कิำ

$\begin{array}{ll}5 & 0 \\ 0 & 0 \\ 0 & 0 \\ 0 & 0 \\ 0 & 0 \\ 0\end{array}$

임

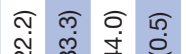

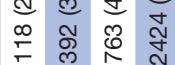

市

กิ

过造

స్

in

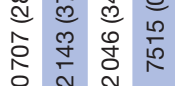

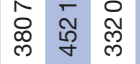

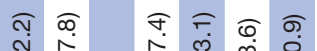

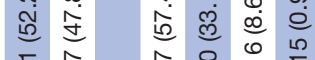

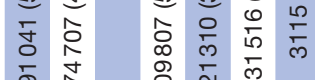

단

वे ते ले

年考

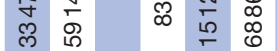

ल $\bar{c} \widehat{\omega} \overline{\mathrm{m}}$

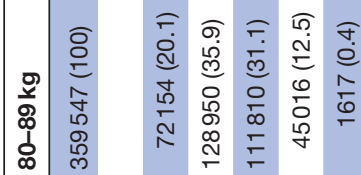

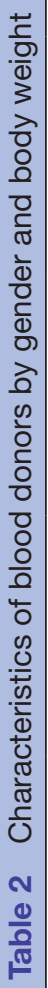

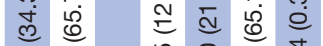

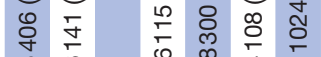

零
ल $\widehat{0}$ ब

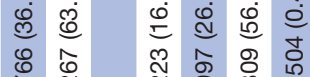

岱

है

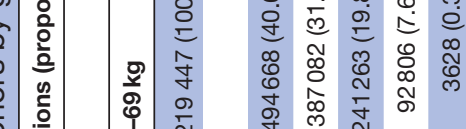

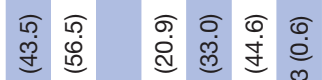

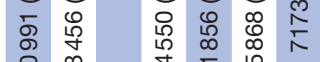

ô

\section{$\vec{\varepsilon}$}

ल)

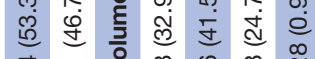

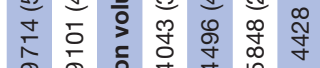

学等

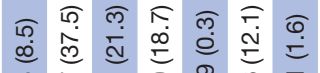

俩

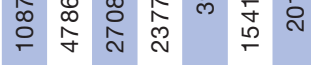

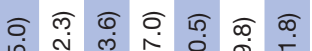

๒

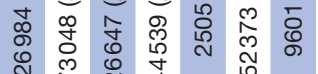

م.

สิ

ㄴำ

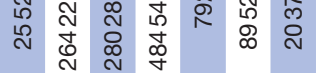

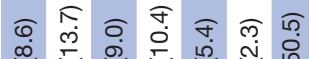

is

क्ष

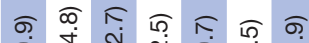

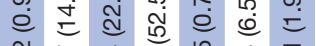

贷点

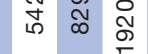

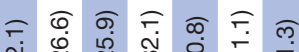

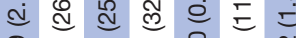

年

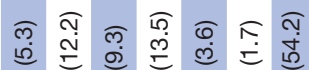

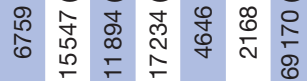

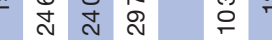

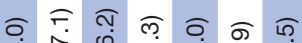

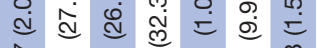

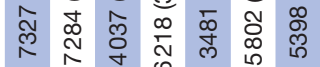

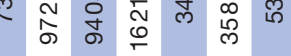

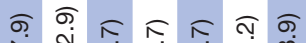

ปे लै

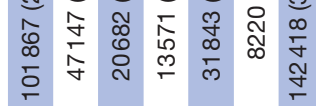

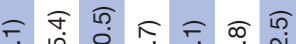

Q

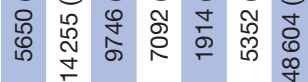

ल बิ बढ़

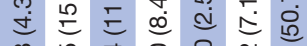

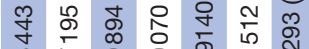

ᄂ

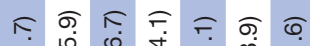

ब웅

-

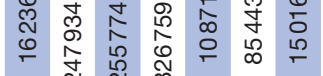

等

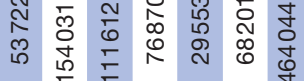

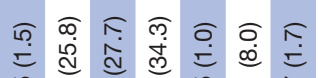

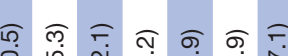

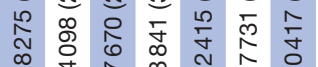

든

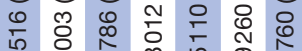

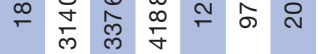

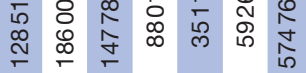

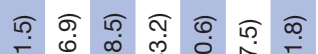

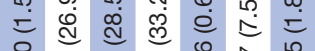

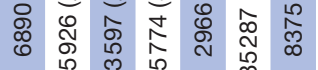

$\stackrel{\text { N }}{\sim} \stackrel{\text { m }}{\sim}$

बิণ

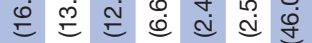

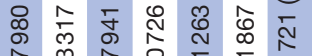


Table 3 Logistical regression models predicting donations of $300 \mathrm{~mL}$ or more per donation by gender

\begin{tabular}{|c|c|c|c|c|}
\hline \multirow[b]{2}{*}{ Independent variables } & \multicolumn{2}{|l|}{ Male } & \multicolumn{2}{|l|}{ Female } \\
\hline & OR (95\% Cl) & $P$ values & OR (95\% Cl) & $P$ values \\
\hline \multicolumn{2}{|c|}{ Age, reference category: $18-25$} & $<0.001$ & & $<0.001$ \\
\hline $26-35$ & $0.92(0.92$ to 0.93$)$ & $<0.001$ & $0.83(0.82$ to 0.83$)$ & $<0.001$ \\
\hline $36-45$ & 0.91 (0.90 to 0.92$)$ & $<0.001$ & 0.77 (0.76 to 0.77$)$ & $<0.001$ \\
\hline $46-55$ & 0.78 (0.77 to 0.78$)$ & $<0.001$ & 0.68 (0.67 to 0.69$)$ & $<0.001$ \\
\hline $56+$ & 0.91 (0.86 to 0.95$)$ & $<0.001$ & 1.07 (0.98 to 1.18$)$ & 0.131 \\
\hline \multicolumn{2}{|c|}{ Male weight, reference category: $50-59 \mathrm{~kg}$} & $<0.001$ & & \\
\hline $60-69 \mathrm{~kg}$ & 2.05 (2.03 to 2.06 ) & $<0.001$ & & \\
\hline $70-79 \mathrm{~kg}$ & 2.87 (2.85 to 2.90$)$ & $<0.001$ & & \\
\hline $80-89 \mathrm{~kg}$ & 3.92 (3.87 to 3.97 ) & $<0.001$ & & \\
\hline $90+\mathrm{kg}$ & $5.58(5.44$ to 5.73$)$ & $<0.001$ & & \\
\hline \multicolumn{4}{|c|}{ Female weight, reference category: $45-50 \mathrm{~kg}$} & $<0.001$ \\
\hline \multicolumn{3}{|l|}{$50-59 \mathrm{~kg}$} & 2.90 (2.88 to 2.92$)$ & $<0.001$ \\
\hline \multicolumn{3}{|l|}{$60-69 \mathrm{~kg}$} & 4.78 (4.78 to 4.83$)$ & $<0.001$ \\
\hline \multicolumn{2}{|l|}{$70+\mathrm{kg}$} & & 7.11 (6.99 to 7.23$)$ & $<0.001$ \\
\hline \multicolumn{2}{|c|}{ Education, reference category: elementary school } & $<0.001$ & & $<0.001$ \\
\hline Middle school & 1.05 (1.03 to 1.08$)$ & $<0.001$ & 1.09 (1.06 to 1.11$)$ & $<0.001$ \\
\hline High school & 0.78 (0.76 to 0.80$)$ & $<0.001$ & 0.89 (0.87 to 0.91$)$ & $<0.001$ \\
\hline University* & 0.50 (0.48 to 0.51$)$ & $<0.001$ & 0.54 (0.53 to 0.55$)$ & $<0.001$ \\
\hline Postgraduate & 0.29 (0.28 to 0.30$)$ & $<0.001$ & 0.34 (0.33 to 0.36$)$ & $<0.001$ \\
\hline Other+ & 0.70 (0.68 to 0.72$)$ & $<0.001$ & 0.66 (0.65 to 0.68$)$ & $<0.001$ \\
\hline \multicolumn{2}{|c|}{ Occupation, reference category: student } & $<0.001$ & & $<0.001$ \\
\hline Clerk & $0.74(0.73$ to 0.75$)$ & $<0.001$ & 1.17 (1.15 to 1.18$)$ & $<0.001$ \\
\hline Workers & $0.86(0.84$ to 0.87$)$ & $<0.001$ & 1.21 (1.19 to 1.23$)$ & $<0.001$ \\
\hline farmers & $0.76(0.75$ to 0.78$)$ & $<0.001$ & $1.28(1.26$ to 1.30$)$ & $<0.001$ \\
\hline Medical worker & 0.39 (0.39 to 0.40$)$ & $<0.001$ & 0.58 (0.58 to 0.59$)$ & $<0.001$ \\
\hline Public service & $0.48(0.47$ to 0.49$)$ & $<0.001$ & 0.71 (0.69 to 0.72$)$ & $<0.001$ \\
\hline Other++ & $0.74(0.73$ to 0.75$)$ & $<0.001$ & $1.21(1.19$ to 1.22$)$ & $<0.001$ \\
\hline \multicolumn{2}{|c|}{ Year, reference category: 2006} & $<0.001$ & & $<0.001$ \\
\hline 2007 & $1.26(1.24$ to 1.27$)$ & $<0.001$ & 1.25 (1.23 to 1.27$)$ & $<0.001$ \\
\hline 2008 & 2.18 (2.15 to 2.21$)$ & $<0.001$ & 2.23 (2.20 to 2.26$)$ & $<0.001$ \\
\hline 2009 & 2.39 (2.36 to 2.43$)$ & $<0.001$ & 2.37 (2.33 to 2.40$)$ & $<0.001$ \\
\hline 2010 & 2.30 (2.27 to 2.34$)$ & $<0.001$ & 2.11 (2.08 to 2.14$)$ & $<0.001$ \\
\hline 2011 & 1.85 (1.83 to 1.87$)$ & $<0.001$ & 1.67 (1.65 to 1.70$)$ & $<0.001$ \\
\hline 2012 & 1.46 (1.44 to 1.48$)$ & $<0.001$ & 1.23 (1.21 to 1.25$)$ & $<0.001$ \\
\hline 2013 & 1.52 (1.50 to 1.54$)$ & $<0.001$ & $1.24(1.22$ to 1.26$)$ & $<0.001$ \\
\hline 2014 & 1.71 (1.68 to 1.73 ) & $<0.001$ & 1.36 (1.34 to 1.37$)$ & $<0.001$ \\
\hline 2015 & 1.70 (1.68 to 1.72$)$ & $<0.001$ & 1.32 (1.30 to 1.34$)$ & $<0.001$ \\
\hline Constant & 2.31 & $<0.001$ & 0.68 & $<0.001$ \\
\hline
\end{tabular}

kg, kilogram; mL, millilitre.

while the pattern of increasing body weight is positive in the short-term because of the increased likelihood of repeated donations among donors and more volume donated each time, it may also reduce the likelihood that donors will be healthy enough to meet the physical health eligibility criteria for blood donation. Based on the assumption that blood volume can be estimated as $70 \mathrm{~mL} / \mathrm{kg}$, therefore, the heavier the body weight, the greater the amount volume of blood, the less impact of blood donation on the body. Given that the blood volume 
Table 4 Logistical regression models predicting repeated donations by gender

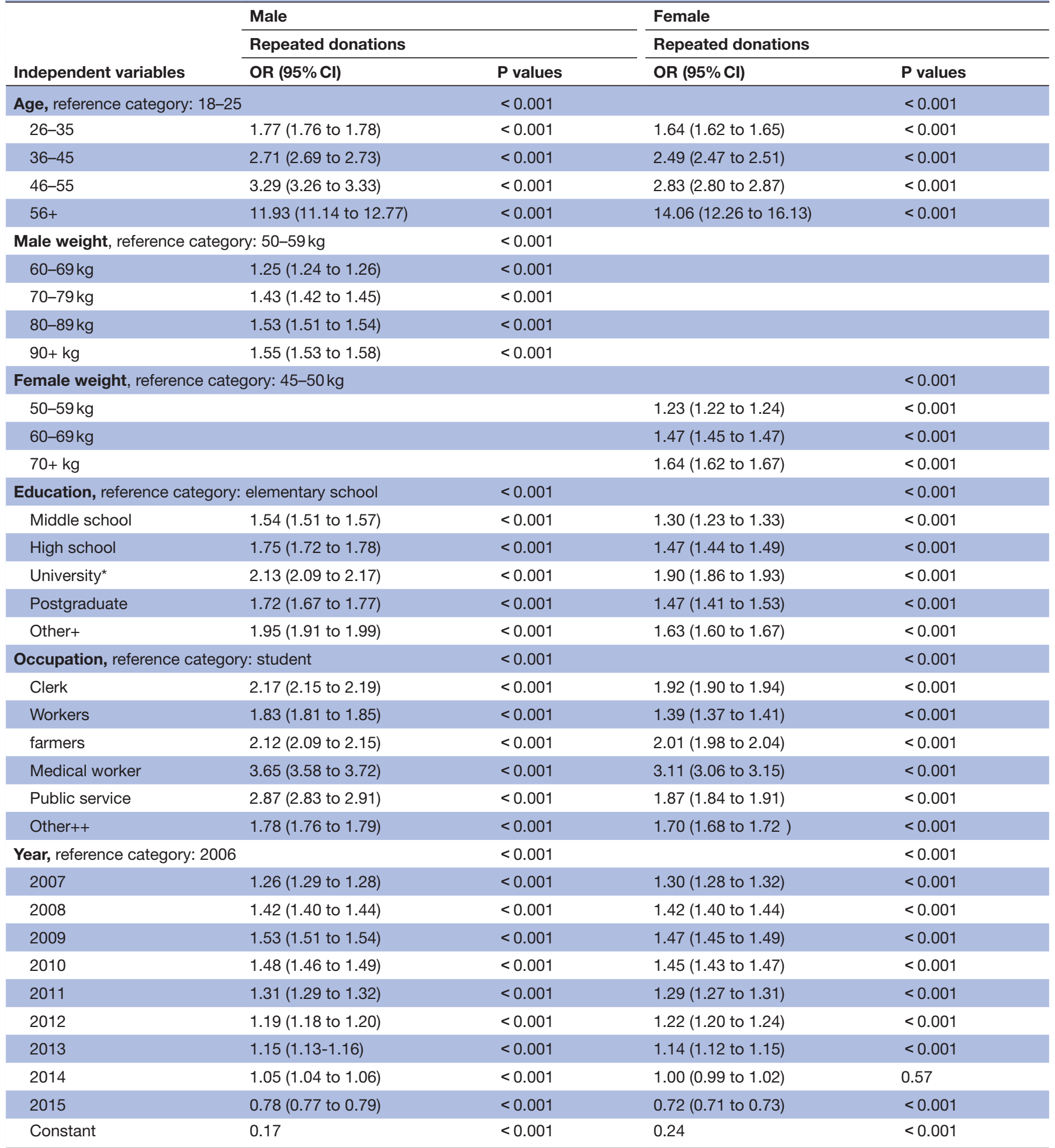

This is multivariable logistical regression model.

*'University' including junior college degree and bachelor.

+'other' including lower than elementary school or higher than postgraduate.

++ 'other' including missing and other types of occupations.

kg, kilogram; $\mathrm{mL}$, millilitre.

of each donation is changing gradually from $200 \mathrm{~mL}$ to $300 \mathrm{~mL}$ or $400 \mathrm{~mL}$, we might say that long-term blood donation publicity in Zhejiang has played a positive role.
Additionally, the body weight gain year by year has played a positive role in influencing the choice of high volume blood donation and the possibility to participate in 
multiple blood donations. According to the 2015 report on Nutrition and Chronic Diseases of Chinese people, the average height of adult males and females aged 18 years and above in China was $167.1 \mathrm{~cm}$ and $155.8 \mathrm{~cm}$, respectively, with average body weights of $66.2 \mathrm{~kg}$ and $57.3 \mathrm{~kg}$, respectively. ${ }^{43}$ Compared with the average body weight of donors (figure 4-7), male donors are a little heavier than the average population, but female donors are a little lighter than the average population. However, as we mentioned, overnutrition and overweight were among the most significant contributors to ill-health. ${ }^{18}$ Most obese people can not pass the blood screen even if they want to donate. Controlling body weight within a reasonable range is beneficial to individual health and helpful for expanding the pool of potential donors.

Results from the multivariable regression analysis suggest future donor recruitment and retention approaches should consider tailoring messages based on demographical characteristics such as age, gender and body weight. For example, for donors with all ages, recuirtment messages should focus on the benefit of repeated donation. We should strengthen the education that donating $300 \mathrm{~mL}$ or more does not affect health through the relationship analysis between donation volume and health, etc. For the majority of lower weight donors (young adults), the message should focus on promoting a healthy diet for better nutrition and health. On the other hand, public health messages for the middle-aged individuals should include a healthy diet and active lifestyle due to high prevalence of unhealthy body weight gain due in large part to rapid changing economical, social and physical environment, as well as to a diet that is high in calorie-dense-nutrition-poor foods.

This study has several limitations. The 38 blood banks in Zhejiang province may not be representative of blood centres in other regions in China. While these 38 blood banks are geographically diverse, they all represent relatively developed areas in eastern China. Less economically developed provinces were not included in this study. In addition, only limited demographical information were collected by the blood donation data management system due to protection of donor privacy and promotion of blood donation collection efficiency. Future studies should expand the data collection such as height and so on, to help better understand the individual and group level facilitators and barriers to whole blood donation.

Acknowledgements We thank Zhejiang Provincial Natural Science Foundation for supporting the study. We thank Ronald R Ingram and Jedidiah Peterson for helping proofread this manuscript. We are grateful for Editor and Reviewers for very helpful comments on the paper.

Contributors Each of the authors contributed to the preparation and editing of the manuscript. WH, HM and QH designed the study, collected the data and conducted the literature review. WH and $\mathrm{HM}$ analysed the data and drafted the manuscript. $\mathrm{QH}$, $\mathrm{LF}$ and $\mathrm{XQ}$ contributed to data interpretation and critical revisions of the manuscript. All authors approved of the final paper version.

Funding This work was supported by the Natural Science Foundation of Zhejiang Province grant number LY17G030020.

Competing interests None declared.

\section{Patient consent for publication Not required.}

Ethics approval This study was approved by Medical Ethics Committee of Blood Centre of Zhejiang Province (NO. 2006002). There is no any medical information that can identify the blood donor's identity in this paper.

Provenance and peer review Not commissioned; externally peer reviewed. Data sharing statement No additional data are available.

Open access This is an open access article distributed in accordance with the Creative Commons Attribution Non Commercial (CC BY-NC 4.0) license, which permits others to distribute, remix, adapt, build upon this work non-commercially, and license their derivative works on different terms, provided the original work is properly cited, appropriate credit is given, any changes made indicated, and the use is non-commercial. See: http://creativecommons.org/licenses/by-nc/4.0/.

\section{REFERENCES}

1. World Health Organization. Blood safety and availability. http://www. who.int/mediacentre/factsheets/fs279/en/

2. Jóhannsdóttir V, Gudmundsson S, Möller E, et al. Blood donors in Iceland: a nationwide population-based study from 2005 to 2013. Transfusion 2016;56:1654-61.

3. National Health Commission of the People's Republic of China website. Interpretation of the "Notice on 2016 Blood Safety Technology Verification. http://www.nhc.gov.cn/yzygj/s7658/201704/ d40d657217dd4ead8dd37ee7d38d22d4.shtml

4. Zhu Yongming G. Blood Transfusion Services Blue Book: China Blood Transfusion Industry Development Report (2016). Beijing, China: Social Science Literature Press, 2016:4

5. National Health Commission of the People's Republic of China website. Bulletin on the 2017 National Blood Safety Technology Verification. http://www.nhc.gov.cn/yzygj/s7658/201805/77ba8072 6c694b188e617f0d43d23856.shtml

6. Zhu Y, Xie D, Wang X, et al. Challenges and Research in Managing Blood Supply in China. Transfus Med Rev 2017;31.

7. Veldhuizen IJ, Doggen CJ, Atsma F, et al. Donor profiles: demographic factors and their influence on the donor career. Vox Sang 2009;97:129-38.

8. Atsma F, Veldhuizen I, de Vegt F, et al. Cardiovascular and demographic characteristics in whole blood and plasma donors: results from the Donor InSight study. Transfusion 2011;51:412-20.

9. Custer B, Schlumpf K, Simon TL, et al. Demographics of successful, unsuccessful and deferral visits at six blood centers over a 4-year period. Transfusion 2012;52:712-21.

10. Burgdorf KS, Simonsen J, Sundby A, et al. Socio-demographic characteristics of Danish blood donors. PLoS One 2017;12:e0169112.

11. National Bureau of Statistics. Statistical Communiqué of the People's Republic of China on the 2017 National Economic and Social Development. 2018. http://www.stats.gov.cn/english/PressRelease/ 201802/t20180228 1585666.html

12. Yang XG, Yp L, Gs M, et al. Analysisof the Height and Weight of Residents in China in Recent Ten Years and the Trend of Changes in Recent Ten Years. Chinese Journal of Epidemiology 2005;26:489-93.

13. Eder A, Goldman M, Rossmann S, et al. Selection criteria to protect the blood donor in North America and Europe: past (dogma), present (evidence), and future (hemovigilance). Transfus Med Rev 2009;23:205-20.

14. Eder AF, Dy BA, Kennedy JM, et al. Improved safety for young whole blood donors with new selection criteria for total estimated blood volume. Transfusion 2011;51:1522-31.

15. Almutairi $\mathrm{H}$, Salam $M$, Alajlan $\mathrm{A}$, et al. Incidence, predictors and severity of adverse events among whole blood donors. PLoS One 2017;12:e0179831 https://doi.org/.

16. Nishimori H, Fujii N, Fujii K, et al. Predictors of vasovagal reactions during preoperative autologous blood donation: a single-institution analysis. Int J Hematol 2017;105:812-8.

17. Newman BH. Vasovagal reaction rates and body weight: findings in high- and low-risk populations. Transfusion 2003;43:1084-8.

18. Kopelman P. Health risks associated with overweight and obesity. Obes Rev 2007;8 Suppl 1:13-17.

19. Gregg EW, Shaw JE. Global Health Effects of Overweight and Obesity. N Engl J Med 2017;377:80-1.

20. Ministry of Health of the People's Republic of China. Blood station management methods. http://www.gov.cn/flfg/2005-12/06/content_ 118502.htm

21. von Elm E, Altman DG, Egger M, et al. The Strengthening the Reporting of Observational Studies in Epidemiology (STROBE) Statement. Epidemiology 2007;18:800-4. 
22. Newman B. Iron depletion by whole-blood donation harms menstruating females: the current whole-blood-collection paradigm needs to be changed. Transfusion 2006;46:1667-81.

23. Peffer K, Verbeek AL, Swinkels DW, et al. Donation intensity and metabolic syndrome in active whole-blood donors. Vox Sang 2015;109:25-34.

24. Yang BC, Shao C-P, Zhang Y-Y. Lingkui Kong, 1 and Yun-Ping Xu Two decades of voluntary non-remunerated blood donation in Shenzhen, China. TRANSFUSION 2015;55:1108-14.

25. Ou Y, Yau KK, Poon CM, et al. Donation frequency and its association with demographic characteristics--a 1-year observational study. Transfus Med 2015;25:366-73.

26. Lan DS, Jz W, Zeng J, et al. The age distribution and its changing trend of voluntary non-remunerated blood donors in Fuzhou from 2006 to 2013. Chinese Journal of Blood Transfusion 2014;27:7331.

27. Zeng YQ, Luo XR, Xiao SY. Analysis of affect Zhuzhou City residents repeated blood donation factor. Chinese Journal of Blood Transfusion $2011 ; 24: 144$

28. Wittock N, Hustinx L, Bracke P, et al. Who donates? Cross-country and periodical variation in blood donor demographics in Europe between 1994 and 2014. Transfusion 2017;57:2619-28.

29. Booth C, Allard S. Blood transfusion. Medicine 2017;45:244-50.

30. Shander A, Isbister J, Gombotz H. Patient blood management: the global view. Transfusion 2016;56(Suppl 1):S94-S102.

31 Snyder M. Doing Good for Self and Others: Volunteerism and the Psychology of Individual and Collective Action. Paper presented at the biannual meeting of the Society for the Psychological Study of Social issues. Minneapolis, MN, 2000.

32. Misje $\mathrm{AH}$, Bosnes V, Gåsdal $\mathrm{O}$, et al. Motivation, recruitment and retention of voluntary non-remunerated blood donors: a surveybased questionnaire study. Vox Sang 2005;89:236-44.
33. Mathew SM, King MR, Glynn SA, et al. Opinions about donating blood among those who never gave and those who stopped: a focus group assessment. Transfusion 2007;47:729-35.

34. Callero PL, Piliavin JA. Developing a commitment to blood donation; the impact of one's first experience. J App/SocPsychol 1983;15:826-31.

35. Godin G, Conner M, Sheeran P, et al. Determinants of repeated blood donation among new and experienced blood donors. Transfusion 2007;47:1607-15.

36. Bagot KL, Murray AL, Masser BM. How Can We Improve Retention of the First-Time Donor? A Systematic Review of the Current Evidence. Transfus Med Rev 2016;30:81-91.

37. Kasraian L, Tavassoli A, Leila Kasraian A. Relationship between first-year blood donation, return rate for subsequent donation and demographic characteristics. Blood Transfus 2012;10:448-52.

38. Sanchez AM, Ameti DI, Schreiber GB, et al. The potential impact of incentives on future blood donation behavior. Transfusion 2001;41:172-8.

39. Schreiber GB, Sharma UK, Wright DJ, et al. First year donation patterns predict long-term commitment for first-time donors. Vox Sang 2005;88:114-21.

40. Ownby HE, Kong F, Watanabe K, et al. Analysis of donor return behavior. Retrovirus Epidemiology Donor Study. Transfusion 1999;39:1128-35.

41. Zhejiang Statistical Information Website. The main data bulletin of the sample survey on population changes in Zhejiang Province in 2016. Zhejiang Province, Economic and Social Development. http://tjj.zj. gov.cn/tjgb/rkcydcgb/201702/t20170208_191340.html

42. Kasraian L. Causes of discontinuity of blood donation among donors in Shiraz, Iran: cross-sectional study. Sao Paulo Med J 2010;128:272-5.

43. State Council Information Office. Chinese residents nutrition and chronic disease status report. 2015. http://www.nhfpc.gov.cn/zhuz/ xwfb/201506/6b4c0f873c174ace9f57f11fd4f6f8d9.shtml 